\title{
Arrhythmia-induced Cardiomyopathy: An Article Review
}

\author{
Sidhi Laksono Purwowiyoto ${ }^{1,2 *}$ (D) , Hillary Kusharsamita ${ }^{3}$ \\ ${ }^{1}$ Department of Cardiology and Vascular Medicine, RS Pusat Pertamina, South Jakarta, Indonesia; ${ }^{2}$ Faculty of Medicine, \\ Universitas Muhammadiyah Prof. DR. Hamka, Tangerang, Indonesia; ${ }^{3}$ Faculty of Medicine, Universitas Diponegoro, \\ Semarang, Indonesia
}

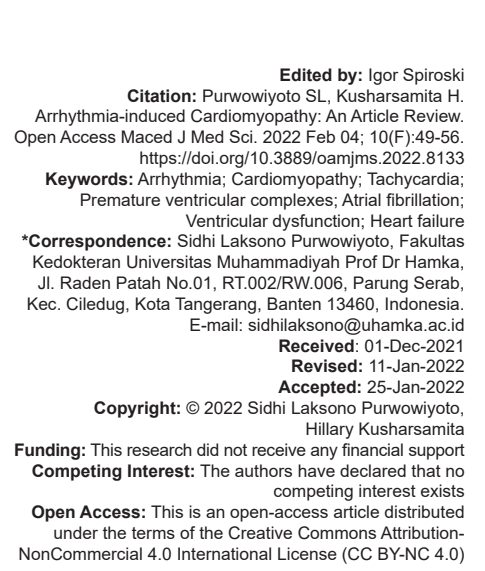

\section{Abstract}

Arrhythmia is one of the significant reversible causes in patients with heart disease and left ventricular dysfunction. Tachycardia, atrial fibrillation, and premature ventricular contractions have indeed been related to arrhythmiainduced cardiomyopathy (CM), a reversible dilated CM. Effective arrhythmia suppression will entirely or partially recover ventricular function, lowering morbidity and mortality. However, the importance of arrhythmia-induced CM (ARiCM) is often underestimated in clinical practice because arrhythmia is often seen as a result rather than a cause of $\mathrm{CM}$, leading in treatment delays and failure to increase the quality of life and better clinical outcomes. This article review aims to summarize the pathomechanisms, and a general approach to the management of ARiCM and its long-term outcomes. ARiCM can cause a variety of clinical signs, ranging from asymptomatic to severe heart failure symptoms. Electrocardiogram, $24 \mathrm{~h}$ Holter monitoring, echocardiography, and cardiac magnetic resonance are all recommended for diagnosis. More research is required to better understand the pathogenesis of ARiCM and to differentiate treatment alternatives to choose the ideal ARiCM management approach

\section{Introduction}

Cardiomyopathy $(\mathrm{CM})$ is a disease that affects the heart muscle and results in ventricular enlargement and systolic dysfunction, in the type of dilated CM (DCM) [1]. One of the essential reversible causes is arrhythmiainduced CM (ARiCM), which is characterized by rapid or irregular ventricular rate and leads to the left ventricular (LV) systolic dysfunction (LVSD) [2]. Reversible causes are essential because the poor long-term prognosis of idiopathic dilated cardiomyopathy [1]. Therefore, treating reversible causes will totally or partially reverse $\mathrm{CM}$. However, in the incidence of pre-existing systemic heart disease, ARiCM can worsen LVSD, making it only partially reversible [2].

Tachyarrhythmias of various types may result in ventricular dysfunction and heart failure (HF). Atrial tachycardia (AT) is a common arrhythmia, if persistent, can lead to ARiCM. T-CMP was observed in $8.3-10 \%$ of patients in trials of focal AT in adults and $28 \%$ in children [3], [4]. What is even more remarkable is that about one-third of patients with atrial fibrillation (AF) and systolic HF consequently have LVSD predominantly, with ARiCM observed in $58-88 \%$ of cases [2].
In patients with LVSD and AF, significant improvement in ejection fraction is $58-68 \%$ after ablation, meaning that many of these patients have reversible ventricular dysfunction related to AF [5], [6]. In different studies of radiofrequency ablation (RFA) of premature ventricular complexes (PVCs), PVC-induced ventricular dysfunction discovered by $7-30 \%$ [7]. As a result of the recognition of several arrhythmias besides tachycardia as a cause of $\mathrm{CM}$, the term ARiCM has developed to include tachycardia-induced CM (T-CM), PVC-induced CM (PVC-CM), and AF-induced CM (AF-CM) [8].

ARiCM has a wide variety of clinical manifestations, solely responsible for the CM (Type 1) or contributing to the underlying CM (Type 2) [9]. In Type 1 ARiCM, successful treatment can turn to complete resolutions, which LV function returns to normal. In contrast, treatment of type 2 ARiCM results in partial resolution of the CM [10]. Unfortunately, the importance of ARiCM is underestimated in clinical practice since arrhythmia is often seen as a result rather than a cause of $\mathrm{CM}$, resulting in a delay of treatment [2].

In this article review, we aim to summarize the cause, pathomechanism, general approach to the management of ARiCM, and its effects, focusing on T-CM, PVC-CM, and AF-CM (Figure 1). 


\begin{tabular}{|c|c|c|c|}
\hline & T-CM & PVC-CM & $A F-C M$ \\
\hline & Chronic Elevate HR & Heart rate irregularity & Elevated HR \\
\hline & & Genetic & Lack of atrial systolic activity \\
\hline & & Dyssynchrony AV Dyssynchrony & Genetic \\
\hline & & Postextrasystolic Potentiation & \\
\hline & & Sympathetic Activation & \\
\hline & $\begin{array}{l}\text { Alternations at myocyte and } \\
\text { myocardium level: myocyte } \\
\text { misalignment } \rightarrow \text { biventricular } \\
\text { dilatation }\end{array}$ & $\begin{array}{l}\text { Abnormalities of the calcium- } \\
\text { induced calcium release } \\
\text { pathway and changes in dyad } \\
\text { activity } \rightarrow \text { contractile } \\
\text { dysfunction }\end{array}$ & $\begin{array}{l}\text { Coordinated atrial contraction: } \\
\text { Reduction cardiac output, and } \\
\text { atrial contraction affects the } \\
\text { cardiac output }\end{array}$ \\
\hline$\frac{8}{3}$ & $\begin{array}{l}\text { Electrical remodelling and } \\
\text { patological Ca homeostasis: } \\
\text { impaired excitation-contraction } \\
\text { coupling and diastolic dysfunction }\end{array}$ & $\begin{array}{l}\text { Histopathological findings: } \\
\text { Minimal/ no fibrosis without } \\
\text { an elevated inflammation/ } \\
\text { apoptosis }\end{array}$ & $\begin{array}{l}\text { Genetic mutations: } \\
\text { Impaired contractile function, } \\
\text { cellular integrity, and/or } \\
\text { cytoskeletal structure }\end{array}$ \\
\hline 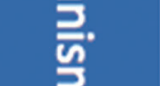 & $\begin{array}{l}\text { Time-dependent ventricular } \\
\text { remodeling }\end{array}$ & Electrophysiological remodeling & \\
\hline & & $\begin{array}{l}\text { Genetic R222Q missense: } \\
\text { rate-dependent ectopy purkinje } \\
\text { correlated with CM }\end{array}$ & \\
\hline Therapy & \multicolumn{3}{|c|}{ Ablation or antiarrhythmic drug } \\
\hline \multirow{6}{*}{ 窝 } & Normalized LVEF & Normalized LVEF & Normalized LVEF \\
\hline & LV mass rises by $26 \%$ & \multirow{2}{*}{$\begin{array}{l}\text { Possible cause for recurrent PVC- } \\
\mathrm{CM} \text { : Myocarditis }\end{array}$} & \\
\hline & LV remains dilated & & \\
\hline & Fibrosis continue to exist & & \\
\hline & Rapid reduction in pro-BNP & & \\
\hline & $\begin{array}{l}\text { Myocytes continue to exhibit } \\
\text { contractile dysfunction }\end{array}$ & & \\
\hline
\end{tabular}

Figure 1: Summary pathomechanism of ARICM. T-CM: Tachycardia-induced cardiomyopathy, PVC-CM: Premature ventricular complexinduced cardiomyopathy, AF-CM: Atrial fibrillation-induced cardiomyopathy, HR: Heart rate, AV: Atrioventricular, LV: Left ventricular, LVEF: Left ventricular ejection fraction

\section{Tachycardia-induced CM}

\section{Definition and prevalence}

T-CM is a type of reversible myocardial dysfunction induced by persistent arrhythmias that have been observed in experimental animals as well as in individuals with supraventricular and ventricular tachyarrhythmias [3]. Gossage et al. first described T-CMP in a patient with $\mathrm{AF}$ and rapid ventricular response in 1913. Following that, in an animal model, the development of reversible HF with rapid pacing was demonstrated. T-CMP was then coined to describe the development of ventricular dysfunction as a result of rapid ventricular rate, regardless of the type of tachycardia [1].

T-CM shows the presence of reversible LV dysfunction caused only by an increase in ventricular rates. The risk of developing $\mathrm{T}-\mathrm{CM}$ is determined by the type of tachycardia and the tachycardia's rate and duration. T-CM has been confirmed to appear weeks, months, or years after the onset of tachycardia [8]. 
T-CM has been documented in $10 \%$ of patients with AT and $37 \%$ of patients with persistent AT. Furthermore, the highest correlation with T-CM was found in permanent junctional reciprocating tachycardia in up to $50 \%$ since it often manifests as a persistent supraventricular tachycardia (SVT) [11]. In up to $25 \%$ of cases, atrial flutter is associated with LV dysfunction, with most cases increasing their LV function following cessation of the arrhythmia [12]. In addition, a $96 \%$ complete full recovery of LV function was discovered from a successful catheter ablation in 25-30 patients with T-CM [10].

\section{Mechanism and pathophysiology}

Understanding the pathomechanism of T-CM has relied on animal models. Animals exposed to chronic tachycardia using continuous pacing develop HF manifestations, LVSD, and LV biventricular dilatation, reduction in myocardial blood flow, as well as a rise in LV wall stress, end-diastolic pressure, and volume [13]. All animal models demonstrated timedependent ventricular remodeling in association with the development of HF. These physiological changes will progress, which include a 1 week plateaus of decrease in systemic blood pressure, LV, and pulmonary artery pressure, while cardiac output, ejection fraction, and volumes begin to decline over the next 4 weeks, with the onset of symptomatic HF occurring within 2-3 weeks [14].

Chronic rapid pacing also causes alterations at the myocyte and myocardium levels. The main changes observed are depletion of myocyte energy, mitochondrial dysfunctions with increased oxidative enzymes, myocyte elongations, reduced myocyte attachment with the basement membrane, activations of proapoptotic cascades, and myocyte loss. There is also a significant depletion of the extracellular matrix. This weakens myocyte support and induces myocytes' misalignment, leading to biventricular dilatation with no improvement or ventricular wall thinning [1], [15], [16]. Electrical remodeling and pathological $\mathrm{Ca}$ homeostasis have also been observed in T-CM models, which are believed to be responsible for impaired excitationcontraction coupling and diastolic dysfunction [13], [17]. The only total $\mathrm{Ca}$ cycling, $\mathrm{Ca}$ channel inhibition, and basal ATPase activity have shown a statistically relevant association with a decrease in the LV ejection fraction (LVEF) [16].

As tachycardia pacing is stopped, the right atrial and arterial pressures normalize, with substantial improvement of the LVEF and cardiac activity within $48 \mathrm{~h}$ and total normalization within 1-2 weeks [13]. However, after a week, when tachycardia is resolved, $26 \%$ of LV mass raised, the LV still dilated, and myocytes remain to exhibit contractile dysfunction [8]. Furthermore, despite the normalization of the LV function, specific changes, such as fibrosis, continue to exist [17].

\section{Clinical Presentation and Diagnosis}

Clinical trials have discovered a variable time between the onset of arrhythmia signs and T-CM development, varying from 3 until 120 days with an average LVEF is $32 \%$ [18]. Regardless of tachyarrhythmia, symptoms of HF occur earlier in patients with higher rates of tachycardia [14], [17], such as those with persistent atrial flutter or tachycardia with 2:1 atrioventricular (AV) conduction at rates of 150 beats/min. A latest clinical research discovered that T-CM had more serious LV dysfunction than dilated and inflammatory CM [19].

Palpitations are the most often reported symptoms, followed by HF Class III to IV and syncope/pre-syncope, with the remaining showing no symptoms [20]. While sudden cardiac death is rare, it has been confirmed in up to $8-12 \%$ of cases after treatment and CM resolution [18], [21]. However, T-CM can appear as persistent or paroxysmal tachycardia, and it should be expected in patients with the LV dysfunction and a previous, chronic, or recurrent paroxysmal tachycardia with no obvious etiology. If the tachycardia is present, despite underlying secondary CM, a superimposed T-CM should be considered. Therefore, an ambulatory electrocardiogram (ECG) monitor is critical to validate or exclude T-CM for at least 2 weeks [18], [22].

Other etiologies can be ruled out with the aid of an echocardiogram and cardiac magnetic resonance imaging. T-CM is distinguished by DCM, moderate-tosevere biventricular systolic dysfunction, and normal LV septal and posterior wall thickness [17]. Natriuretic peptide (BNP) and pro-BNP are often elevated in heart disease and CM patients [16], [18]. Furthermore, a rapid reduction in pro-BNP within a week of tachycardia elimination supports T-CM [16].

However, T-CM's definitive diagnosis can only be confirmed after regeneration of LV systolic function within 1-6 months of tachyarrhythmia elimination [22]. Although no preliminary imaging or biochemical measurement can conclusively differentiate AriCMP from other kinds of non-ischemic DCM, numerous indicators have been discovered that assist to predict considerable LV functional recovery after optimal arrhythmia management [23]

A recent research examined on endomyocardial biopsies from 189 people with non-ischemic newonset HF, 19 of whom were classified as ARiCMP retrospectively. The ARICMP cases were compared to 91 patients with inflammatory $\mathrm{CM}$ and 79 individuals with DCM. The researchers observed that ARiCMP patients' LV biopsies exhibited greater levels of major histocompatibility complex Class II expression and more CD68 macrophage infiltration than DCM. Mitochondria were disproportionately distributed toward the intercalated disks in compared to healthy individuals. Myocardial fibrosis was also identified in ARiCMP, 
however, it was less severe than in inflammatory $\mathrm{CM}$ and DCM [19].

Furthermore, ARiCMP patients had smaller LV cavities than DCM patients with accompanying arrhythmia. ARiCMP is also indicated by early right ventricular systolic failure on MRI. A recent study showed the utilization of longitudinal strain (LS) by echocardiographic speckle tracking in predicting LV functional recovery in clinically suspected ARiCMP patients. Patients with ARiCMP exhibited a more substantial reduction in apical LS compared to the mid and basal segments at baseline, whereas patients with persisting LV dysfunction after arrhythmia treatment had a greater reduction in LS in the basal segments [23].

\section{PVC-CM}

\section{Definition and prevalence}

PVCs were assumed to be benign. However, CM caused by recurrent PVCs in otherwise healthy cardiac has been observed in the recent decade [24]. Although PVC-CM was initially described as T-CMP, they did not have prolonged tachycardia, and distinct pathomechanisms might to contribute to ventricular dysfunction [1]. As a result, the latest 2016 AHA Research Statement on dilated cardiomyopathies acknowledges PVC-CM as a separate clinical classification. PVC-CM is characterized as the development of LV dysfunction independently as a result of frequent PVCs. In living humans, PVC-CM is defined by an enhancement in LVEF following PVC therapy or by the solely presence of PVCs in a structurally normal heart and later LV dysfunction [17]. Furthermore, superimposed PVC-CM is characterized as an increase in LVEF of at least $10 \%$ due to frequent PVCs in a previously established CM [18].

The prevalence of ARiCM in PVCs patients has been estimated to range in 9-34\% [9]. The prevalence of PVCs in ECG is reported between $1 \%$ and $4 \%$ in patients without heart disease. On the other hand, the prevalence of PVCs is considerably higher during ambulatory ECG recording [25]. The wide variations of PVCs frequency can demonstrate this over time. PVC incidence ranges with age, varying from $1 \%$ in children under 11 to approximately $70 \%$ in subjects 75 and older. PVCs were often linked with HF, DCM, coronary heart disease, and post-myocardial infarction [26].

\section{Mechanism and pathophysiology}

In the presence of frequent PVCs, ARiCM development is multifactorial. Heart rate irregularity, pre- and intraventricular dyssynchrony, AV dyssynchrony, post-extrasystolic potentiation, and sympathetic activation are the major suggested mechanisms [27]. The predominant cause of PVC-CM contractile dysfunction tends to be abnormalities of the calcium-induced calcium release pathway, with changes in dyad activity are suggested as a possible mechanism [22].

Similar to other cardiomyopathies, electrophysiological remodeling found in PVC-CM. However, different histopathology abnormalities also found with minimal or no fibrosis without an elevated inflammation or apoptosis. Mitochondrial analysis has revealed no improvements in phosphorylation oxidative. These results are scientifically confirmed by the absence of scar on cardiac magnetic resonance imaging in patients with PVC-CM [28]. These results also support the hypothesis that primary cause of this reversible $\mathrm{CM}$ is a primary functional abnormality. It is unknown if any cellular and molecular modifications result from CM or the CM's source [22]. Finally, genetic cause, particularly $\mathrm{R} 222 \mathrm{Q}$, can explain why some patients develop PVC-CM while others do not, despite having a similar PVC burden [29].

\section{Clinical Presentation and Diagnosis}

The time window for PVC-CM development is unknown, although it is expected to take months to several years [30]. While animal experiments with persistently high PVC burdens (33-50\%) grow CM within 4 weeks, human studies are inconsistent because of uncertain onset and variant of PVCs [22]. PVC-CM may present with various symptoms, ranging from unclear symptoms to $\mathrm{HF}$ and even syncope [31]. A thorough history and relevant tests such as echocardiography, ECG, and $24 \mathrm{~h}$ Holter monitoring, and cardiac magnetic resonance should be done to rule out other CM causes, while the physical examination is usually normal, except for abnormal heart sounds and signs of HF [22]. The absolute number of PVCs per day and the total burden of PVC-induced $\mathrm{CM}$ are negatively linked to LVEF and directly related to measurements of LV end-diastolic volume [23].

PVC-CM is an exclusion diagnosis that should be considered in patients with recurrent PVCs $>10 \%$ of the time, particularly in non-ischemic CM. The difficulty is determining whether PVCs are the cause of CM or not in patients with CM. Even if CM causes PVCs, if they occur often, they can lead to and exacerbate $\mathrm{CM}$ and HF symptoms; referred to as "superimposed" PVC-CM [32]. In certain cases, echocardiographic and PVC features may aid in the identification of these patients. An echocardiogram should be repeated to validate a normal LV function [22].

Despite the ECG's importance, a continuous ambulatory ECG monitor is needed to boost the high PVC burden's diagnostic yield. A study reported that detecting an individual's full PVC pressure requires at least 6 days. In comparison, a 24 h Holter found only 
$53 \%$ of patients with a PVC burden $>10 \%$, implying that almost half of patients with possible PVC-CM diagnosis were missed [24]. Another study introduced a PVC burden of $13 \%$ as the optimal cutoff for estimating LV recovery with $100 \%$ sensitivity and $85 \%$ precision of independent of coexisting systemic heart disease [33].

PVC-CM is distinguished by mild-to-severe LVSD, LV dilatation, mild mitral regurgitation, and left atrial (LA) enlargement that resolves in 2-12 weeks after eliminating PVCs. Cardiac imaging is critical for detecting LV dysfunction and raising the suspicion of PVC-CM in patients with a high PVC burden $(>10 \%)$ [34]. Cardiac magnetic resonance with late gadolinium enhancement provides the benefit of detecting and measuring scar burden, which may predict the response to PVC control [22].

Recently, myocarditis has been identified as a possible cause for recurrent PVCs and CM, and elevated hs-CRP has been identified as an independent indicator of PVCs in a Chinese population sample [35].

\section{Atrial Fibrillation-Induced CM}

\section{Definition and prevalence}

While AF can induce CM because of the rapid ventricular rate, it was discovered that ventricular dysfunction may also present in patients with AF who had a controlled ventricular rate. As a consequence, the term AF-induced $\mathrm{CM}$ was introduced [22]. AF is the most common cause of ARiCMP in adults. AF and HF are modern epidemics that often coexist and predispose to one another. Patients with AF have a greater chance in the development of HF in the Framingham report [36].

AF-CM is characterized as LV systolic dysfunction in patients with paroxysmal or persistent AF despite adequate rate control. As a result, an ambulatory Holter monitor is essential for ruling out inadequate rate control and T-CM. A common clinical challenge is determining whether the AF is caused by $\mathrm{HF}$ and $\mathrm{CM}$ or conversely [22].

\section{Mechanism and Pathophysiology}

Tachycardia, elevated heart rhythm, lack of atrial systolic activity, and genetic causes are among the pathomechanism processes causing the progression or worsen CM in AF patients. The irregular contraction has negative hemodynamic effects that are unrelated to heart rate [37], [38]. The following factors are also thought to contribute to AF-CM. Irregular heart rate associated with calcium mishandling and loss of atrial contraction associated with sympathetic activation, which contributes to restricted ventricular filling and elevated filling pressures, functional mitral regurgitation, and diastolic dysfunction. Unfortunately, there are no AF-CM animal models available to help researchers better grasp the etiology causation, risk factors, or mechanism [22].

In patients with controlled $\mathrm{AF}$ and LV dysfunction, the LV function improved after AV nodal ablation, which regularizes ventricular rhythm with pacing [37], [38]. Coordinated atrial contraction in AF contributes $20 \%$ of cardiac output and atrial contraction reduction which affects the cardiac output [10], [37].

Aside from rapid ventricular rates, ventricular rate irregularity itself can have negative hemodynamic implications, leading to the LV dysfunction [39]. Moreover, non-ischemic CM has been linked to various genetic mutations structure and contractile function [40]. Over 50 genes have been related to DCM, and they can be present in up to $30 \%$ of patients [41].

\section{Clinical Manifestation and Diagnosis}

AF-CM is an exclusion diagnosis that should be considered in individuals with persistent $\mathrm{AF}$ and non-ischemic CM who do not improve after sufficient medical therapy and rate monitoring. Furthermore, it is uncertain if the time frame or imaging characteristics of AF-CM and T-CM differ, because of the similarities with $\mathrm{T}-\mathrm{CM}$ and the absence of animal models. Therefore, AF-CM diagnosis will only be confirmed if the LV systolic function improves after AF elimination [22].

Since $A F$ in the setting of $\mathrm{HF}$ could be present at the time of the first contact, the initial target should be rate control using beta-blockers digitalis and drug treatment for HF. At the moment, a resting heart rate of $60-100$ beats/min and light exercise heart rate of $<110$ beats/min are advised [2], [42].

\section{General Treatment of ARiCM}

Since arrhythmia suppression will totally or partly reverse ventricular dysfunction in ARiCM, the critical component of management is successful arrhythmia suppression with antiarrhythmic drugs (AADs) or RFA [1]. The strategy used to manage arrhythmia is determined by the degree of arrhythmia, the patient's status, and any known comorbidities. T-CM reversibility is significant after tachycardia is eliminated. However, T-CM's initial treatment should include initiating and optimizing medical treatment for HF and LVSD to 
optimize reverse remodeling. Unfortunately, despite normalization of LVEF, histopathological abnormalities, ventricular dilatation with hypertrophic reaction and diastolic dysfunction, may persist [8], [17], [19]. However, treatment should not be discouraged since it can have significant benefits [22].

RFA has a high success record in treating arrhythmias. If the patient's condition worsens despite adequate rate control, the target should be establishing sinus rhythm. While AADs have a lower success rate ranging from $35 \%$ to $70 \%$ in establishing sinus rhythm, with recurrent adverse effects, AF ablation has shown a higher success rate ranging from $70 \%$ to $90 \%$ and fewer adverse effects [6]. Furthermore, one randomized clinical trial has closely compared amiodarone and AF ablation for rhythm control in AF and HF patients. After 2 years, ablation (70\%) was shown to be superior to amiodarone $(34 \%)$ in terms of establishing sinus rhythm, with less hospitalization and mortality [43].

PVC suppression is deemed effective when PVC strain decreases by more than $80 \%$. In multiple trials, both AADs and RFA demonstrated long-term performance rates ranging from $70 \%$ to $80 \%$. Betablockers are the most prevalently prescribed AAD for frequent PVCs because of its lack of significant side effects. Other AADs, such as amiodarone, dofetilide, sotalol, mexiletine, or flecainide, may be more effective than beta-blockers, but they are associated with severe side effects and a risk of pro-arrhythmia. Because of the elevated mortality found in the CAST study, the current guidelines should not recommend their use [44]. $A$ recent retrospective analysis found that flecainide and propafenone were effective in PVC-CM without raising mortality or ventricular arrhythmia [1]. There is no randomized controlled trial comparing RFA and AADs for PVC suppression, although a one study showed that RFA is more effective than AADs [45]. However, RFA may have slight improvement or may not be possible when PVCs arise from the papillary muscles, epicardium, conduction system, or near the coronaries [1].

\section{Prognosis and Long-Term Outcome of ARiCM}

Following successful therapy, the LV function usually improved within a few weeks to months [46]. Initial outpatient follow-up every 1-3 month should be a routine and should include ECG, ECG Holter monitoring, and an echocardiogram [2]. Depending on the inducing arrhythmia, and despite largely effective catheter ablation, arrhythmia recurrence may occur at a rate range between around 5\% in SVT to nearly $50 \%$ in AF [47]. The recurrence rate of ARiCM after initial effective therapy has not been conclusively determined: $A$ research of 12 patients (observation duration of
5324 months) estimated it to be around $25 \%$, and the risk of recurrence of HF occurred when the heart rate was more than 80 beats/min [48].

According to the current view, if the LV function recovers during arrhythmia therapy, the prognosis for survival is good [5]. Even after a recurrence of arrhythmia, studies have shown a rapid progression of ventricular instability and HF. This progression may be attributed to chronic histopathological abnormalities. Thus, for the treatment of ARiCM, a medication choice with a high efficacy or cure rate should be considered, and recurrences should be monitored [1].

\section{Conclusion}

ARiCM, a reversible $\mathrm{CM}$, manifests in a wide range of clinical manifestation, from asymptomatic to severe HF symptoms. To diagnose this condition, the clinician must preserve a high level of suspicion. Diagnosis requires ECG, $24 \mathrm{~h}$ Holter monitoring, echocardiography, and cardiac magnetic resonance. An adequate diagnosis and treatment of ARiCM will improve LV dysfunction and its related complications, mortality, and health-care costs and support quality of life and long-term prognosis. More study is needed to enhance our understanding of the pathophysiology and to compare therapy options to select the suitable strategy for managing ARiCM.

\section{References}

1. Jain A, Selvaraj RJ. Arrhythmia-induced cardiomyopathy Indian J Clin Cardiol. 2021;11:201-4. https://doi. org/10.1177/2632463620987975

2. Sossalla $S$, Vollmann D. Arrhythmia-induced cardiomyopathy Dtsch Arztebl Int. 2018;115(19):335-41. https://doi.org/10.3238/ arztebl.2018.0335

PMid:29875055

3. Ju W, Yang B, Li M, Zhang F, Chen H, Gu K, et al. Tachycardiomyopathy complicated by focal atrial tachycardia: incidence, risk factors, and long-term outcome. J Cardiovasc Electrophysiol. 2014;25(9):953-957. https://doi.org/10.1111/ jce. 12428

PMid:24716793

4. Kang KT, Etheridge SP, Kantoch MJ, Tisma-Dupanovic S, Bradley DJ, Balaji S, et al. Current management of focal atrial tachycardia in children: A multicenter experience. Circ Arrhythm Electrophysiol. 2014;7(4):664-70. https://doi.org/10.1161/ CIRCEP.113.001423

PMid:25015944

5. Brembilla-Perrot B, Ferreira JP, Manenti V, Sellal JM, Olivier A Villemin $\mathrm{T}$, et al. Predictors and prognostic significance of tachycardiomyopathy: Insights from a cohort of 1269 patients undergoing atrial flutter ablation. Eur $\mathrm{J}$ Heart Fail. 2016;18(4):394-401. https://doi.org/10.1002/ejhf.482 


\section{PMid:26833591}

6. Marrouche NF, Brachmann J, Andresen D, Siebels J, Boersma L, Jordaens $\mathrm{L}$, et al. Catheter ablation for atrial fibrillation with heart failure. N Engl J Med. 2018;378(5):417-27. https://doi. org/10.1056/NEJMoa1707855

PMid:29385358

7. Bogun $F$, Crawford T, Reich S, Koelling TM, Armstrong W, Good E, et al. Radiofrequency ablation of frequent, idiopathic premature ventricular complexes: Comparison with a control group without intervention. Hear Rhythm. 2007;4(7):863-7. https://doi.org/10.1016/j.hrthm.2007.03.003

PMid: 17599667

8. Gopinathannair R, Etheridge SP, Marchlinski FE, Spinale FG, Lakkireddy D, Olshansky B. Arrhythmia-induced cardiomyopathies mechanisms, recognition, and management. J Am Coll Cardiol. 2015;66(15):1714-28. https://doi. org/10.1016/j.jacc.2015.08.038

PMid:26449143

9. Gopinathannair R, Sullivan R, Olshansky B. Tachycardiamediated cardiomyopathy: Recognition and management. Curr Heart Fail Rep. 2009;6(4):257-64. https://doi.org/10.1007/ s11897-009-0035-3

PMid:19948094

10. Sugumar H, Prabhu S, Voskoboinik A, Kistler PM. Arrhythmia induced cardiomyopathy. J Arrhythmia. 2018;34(4):376-383. https://doi.org/10.1002/joa3.12094

PMid:30167008

11. Moore JP, Patel PA, Shannon KM, Albers EL, Salerno JC Stein MA, et al. Predictors of myocardial recovery in pediatric tachycardia-induced cardiomyopathy. Hear Rhythm. 2014;11(7):1163-9. https://doi.org/10.1016/j.hrthm.2014.04.023 PMid:24751393

12. Pizzale S, Lemery R, Green MS, Gollob MH, Tang AS, Birnie DH. Frequency and predictors of tachycardia-induced cardiomyopathy in patients with persistent atrial flutter. Can J Cardiol. 2009;25(8):469-72. https://doi.org/10.1016/ s0828-282x(09)70119-9

PMid:19668781

13. Ling LH, Kalman JM, Ellims AH, Iles LM, Medi C, Sherratt C, et al. Diffuse ventricular fibrosis is a late outcome of tachycardiamediated cardiomyopathy after successful ablation. Circ Arrhythm Electrophysiol. 2013;6(4):697-704. https://doi. org/10.1161/CIRCEP.113.000681 PMid:23884195

14. Shinbane JS, Wood MA, Jensen DN, Ellenbogen KA, Fitzpatrick AP, Scheinman MM. Tachycardia-induced cardiomyopathy: A review of animal models and clinical studies. J Am Coll Cardiol. 1997;29(4):709-15. https://doi.org/10.1016/ s0735-1097(96)00592-x

PMid:9091514

15. Coleman HN, Taylor RR, Pool PE, Whipple GH, Covell JW, Ross J Jr., et al. Congestive heart failure following chronic tachycardia. Am Heart J. 1971;81(6):790-8. https://doi. org/10.1016/0002-8703(71)90083-4 PMid:5088355

16. O'Brien PJ, lanuzzo CD, Moe GW, Stopps TP, Armstrong PW. Rapid ventricular pacing of dogs to heart failure: Biochemical and physiological studies. Can J Physiol Pharmacol. 1990;68(1):34-39. https://doi.org/10.1139/y90-004 PMid:2328442

17. Gupta S, Figueredo VM. Tachycardia mediated cardiomyopathy: Pathophysiology, mechanisms, clinical features and management. Int J Cardiol. 2014;172(1):40-6. https://doi. org/10.1016/j.ijcard.2013.12.180

PMid:24447747
18. Watanabe H, Okamura K, Chinushi M, Furushima H, Tanabe $\mathrm{Y}$, Kodama $\mathrm{M}$, et al. Clinical characteristics, treatment, and outcome of tachycardia induced cardiomyopathy. Int Heart J. 2008;49(1):39-47. https://doi.org/10.1536/ihj.49.39 PMid:18360063

19. Mueller KA, Heinzmann D, Klingel $K$, Fallier-Becker $P$ Kandolf R, Kilias A, et al. Histopathological and immunological characteristics of tachycardia-induced cardiomyopathy. J Am Coll Cardiol. 2017;69(17):2160-72. https://doi.org/10.1016/j. jacc.2017.02.049

PMid:28449778

20. Donghua Z, Jian P, Zhongbo X Donghua Z, Jian P, Zhongbo X, et al. Reversal of cardiomyopathy in patients with congestive heart failure secondary to tachycardia. J Interv Card Electrophysiol. 2013;36(1):27-32. https://doi.org/10.1007/ s10840-012-9727-9

PMid:23090777

21. Nerheim P, Birger-Botkin S, Piracha L, Olshansky B. Heart failure and sudden death in patients with tachycardiainduced cardiomyopathy and recurrent tachycardia. Circulation. 2004;110(3):247-252. https://doi.org/10.1161/01. CIR.0000135472.28234.CC

PMid:15226218

22. Huizar JF, Ellenbogen KA, Tan AY, Kaszala K. Arrhythmia-induced cardiomyopathy: JACC state-of-the-art review. J Am Coll Cardiol. 2019;73(18):2328-44. https://doi.org/10.1016/j.jacc.2019.02.045 PMid:31072578

23. Raymond-Paquin A, Nattel S, Wakili R, Tadros R. Mechanisms and clinical significance of arrhythmia-induced cardiomyopathy. Can J Cardiol. 2018;34(11):1449-60. https://doi.org/10.1016/j. cjca.2018.07.475

PMid:30404750

24. Duffee DF, Shen WK, Smith HC. Suppression of frequent premature ventricular contractions and improvement of left ventricular function in patients with presumed idiopathic dilated cardiomyopathy. Mayo Clin Proc. 1998;73(5):430-3. https://doi. org/10.1016/S0025-6196(11)63724-5

PMid:9581582

25. Loring Z, Hanna P, Pellegrini CN. Longer ambulatory ECG monitoring increases identification of clinically significant Ectopy. Pacing Clin Electrophysiol. 2016;39(6):592-597. https:// doi.org/10.1111/pace.12852

\section{PMid:27005323}

26. Lee GK, Klarich KW, Grogan M, Cha YM. Premature ventricular contraction-induced cardiomyopathy: A treatable condition. Circ Arrhythm Electrophysiol. 2012;5(1):229-36. https://doi. org/10.1161/CIRCEP.111.963348 PMid:22334430

27. Engel G, Cho S, Ghayoumi A, Yamazaki T, Chun S, Fearon WF, et al. Prognostic significance of PVCs and resting heart rate. Ann noninvasive Electrocardiol. 2007;12(2):121-9. https://doi. org/10.1111/j.1542-474X.2007.00150.x

PMid: 17593180

28. HasdemirC, YukselA, CamliD, KartalY, SimsekE,MusayevO, etal. Late gadolinium enhancement CMR in patients with tachycardiainduced cardiomyopathy caused by idiopathic ventricular arrhythmias. Pacing Clin Electrophysiol. 2012;35(4):465-70. https://doi.org/10.1111/j.1540-8159.2011.03324.x PMid:22303908

29. Mann SA, Castro ML, Ohanian M, Guo G, Zodgekar P, Sheu A, et al. R222Q SCN5A mutation is associated with reversible ventricular ectopy and dilated cardiomyopathy. J Am Coll Cardiol. 2012;60(16):1566-73. https://doi.org/10.1016/j. jacc.2012.05.050

PMid:22999724 
30. Ban JE, Park HC, Park JS, Nagamoto Y, Choi JI, Lim HE, et al. Electrocardiographic and electrophysiological characteristics of premature ventricular complexes associated with left ventricular dysfunction in patients without structural heart disease. Europace. 2013;15(5):735-41. https://doi.org/10.1093/ europace/eus 371

PMid:23194696

31. Hwang JK, Park SJ, On YK, Kim JS, Park KM. Clinical characteristics and features of frequent idiopathic ventricular premature complexes in the Korean population. Korean Circ J. 2015;45(5):391-7. https://doi.org/10.4070/kcj.2015.45.5.391 PMid:26413107

32. El Kadri M, Yokokawa M, Labounty T, Mueller G, Crawford T, Good E, et al. Effect of ablation of frequent premature ventricular complexes on left ventricular function in patients with nonischemic cardiomyopathy. Hear Rhythm. 2015;12(4):706-13. https://doi. org/10.1016/j.hrthm.2014.12.017

PMid:25527251

33. Gertz MA, Comenzo R, Falk RH, Fermand JP, Hazenberg BP, Hawkins PN, et al. Definition of organ involvement and treatment response in immunoglobulin light chain amyloidosis $(A L)$ : A consensus opinion from the $10^{\text {th }}$ international symposium on amyloid and amyloidosis, Tours, France, 18-22 April 2004. J Hematol. 2005;79(4):319-28. https://doi.org/10.1002/ ajh.20381

PMid: 16044444

34. Topaloglu S, Aras D, Cagli K, Yildiz A, Cagirci G, Cay S, et al. Evaluation of left ventricular diastolic functions in patients with frequent premature ventricular contractions from right ventricular outflow tract. Heart Vessels. 2007;22(5):328-34. https://doi. org/10.1007/s00380-007-0978-9

PMid:17879025

35. Tung RT, Bauer B, Schelbert H, Lynch JP, Auerbach M, Gupta P, et al. Incidence of abnormal positron emission tomography in patients with unexplained cardiomyopathy and ventricular arrhythmias: The potential role of occult inflammation in arrhythmogenesis. Heart Rhythm. 2015;12(12):2488-98. https:// doi.org/10.1016/j.hrthm.2015.08.014

PMid:26272522

36. Santhanakrishnan R, Wang N, Larson MG, Magnani JW, McManus DD, Lubitz SA, et al. Atrial fibrillation begets heart failure and vice versa: Temporal associations and differences in preserved versus reduced ejection fraction. Circulation. 2016;133(5):484-92. https://doi.org/10.1161/ CIRCULATIONAHA.115.018614

PMid:26746177

37. Clark DM, Plumb VJ, Epstein AE, Kay GN. Hemodynamic effects of an irregular sequence of ventricular cycle lengths during atrial fibrillation. J Am Coll Cardiol. 1997;30(4):1039-45. https://doi.org/10.1016/s0735-1097(97)00254-4 PMid:9316536

38. Cha YM, Redfield MM, Shen WK, Gersh BJ. Atrial fibrillation and ventricular dysfunction: A vicious electromechanical cycle. Circulation. 2004;109(23):2839-43. https://doi.org/10.1161/01. CIR.0000132470.78896.A8

PMid:15197156
39. Prabhu S, Voskoboinik A, Kaye DM, Kistler PM. Atrial fibrillation and heart failure-cause or effect? Heart Lung Circ. 2017;26(9):967-74. https://doi.org/10.1016/j.hlc.2017.05.117 PMid:28684095

40. Burke MA, Cook SA, Seidman JG, Seidman CE. Clinical and mechanistic insights into the genetics of cardiomyopathy. J Am Coll Cardiol. 2016;68(25):2871-86. https://doi.org/10.1016/j. jacc.2016.08.079 PMid:28007147

41. Cahill TJ, Ashrafian H, Watkins $\mathrm{H}$. Genetic cardiomyopathies causing heart failure. Circ Res. 2013;113(6):660-75. https://doi. org/10.1161/CIRCRESAHA.113.300282 PMid:23989711

42. Ponikowski $P$, Voors AA, Anker SD, Bueno H, Cleland JG, Coats AJ, et al. 2016 ESC Guidelines for the diagnosis and treatment of acute and chronic heart failure: The task force for the diagnosis and treatment of acute and chronic heart failure of the European Society of Cardiology (ESC). Developed with the special contribution of the heart failure association (HFA) of the ESC. Eur J Heart Fail. 2016;18(8):891-975. https://doi. org/10.1002/ejhf.592

PMid:27207191

43. Di Biase L, Mohanty P, Mohanty S, Santangeli P, Trivedi C, Lakkireddy $\mathrm{D}$, et al. Ablation versus amiodarone for treatment of persistent atrial fibrillation in patients with congestive heart failure and an implanted device: Results from the AATAC multicenter randomized trial. Circulation. 2016;133(17):1637-44. https://doi. org/10.1161/CIRCULATIONAHA.115.019406 PMid:27029350

44. Pratt CM, Moyé LA. The cardiac arrhythmia suppression trial. Casting suppression in a different light. Circulation. 1995;91(1):245-247. https://doi.org/10.1161/01.cir.91.1.245 PMid:7805210

45. Zhong L, Lee $Y H$, Huang XM, Asirvatham SJ, Shen WK, Friedman PA, et al. Relative efficacy of catheter ablation vs antiarrhythmic drugs in treating premature ventricular contractions: A single-center retrospective study. Heart Rhythm. 2014;11(2):187-193. https://doi.org/10.1016/j.hrthm.2013.10.033 PMid:24157533

46. Zecchin M, Muser D, Vitali-Serdoz L, Buiatti A, Morgera T. Arrhythmias in dilated cardiomyopathy: Diagnosis and treatment. In: Dilated Cardiomyopathy. Cham, $\mathrm{CH}$ : Springer; 2019. p. 149-71. https://doi.org/10.1007/978-3-030-13864-6_10

47. Ling LH, Taylor AJ, Ellims AH, lles LM, McLellan AJ, Lee G, et al. Sinus rhythm restores ventricular function in patients with cardiomyopathy and no late gadolinium enhancement on cardiac magnetic resonance imaging who undergo catheter ablation for atrial fibrillation. Heart Rhythm. 2013;10(9):1334-9. https://doi.org/10.1016/j.hrthm.2013.06.019 PMid:23811081

48. Fujino $T$, Yamashita $T$, Suzuki $S$, Sugiyma $H$, Sagara $K$, Sawada $\mathrm{H}$, et al. Characteristics of congestive heart failure accompanied by atrial fibrillation with special reference to tachycardia-induced cardiomyopathy. Circ J. 2007;71(6):936-40. https://doi.org/10.1253/circj.71.936

PMid:17526993 